\title{
Crime, Maps and Meaning: Views from a Survey on Safety and CCTV in Gemany.
}

\author{
Nils Zurawski and Stefan Czenwinski1
}

\begin{abstract}
In researching CCTV, it must be examined how people assess CCTV measures against the background of their individual knowledge about the technology in question. Research on visual surveillance needs to ask how they sense and perceive cameras. As cameras impact on spatial images and social perceptions, such as security, people's confidence will not be explained solely by showing that cameras do or do not work in reducing crime. For that it is necessary to look at what expectations people have regarding CCTV and its possible shortcomings.

These assumptions provided the research frame for a qualitative study that focused on the assessment of visual surveillance in an urban environment. The study examined what knowledge people actually had about the technology and what meaning was ascribed to the cameras themselves. It seems that knowledge does not inform the meaning, but that the ascribed meaning is generated independently of this knowledge or the lack thereof. The results permit the conclusion that forms of spatial perception that socially produce 'dangerous spaces' have gained prominence. Hazard is then directly ascribed to the spatial context itself. Thus, CCTV seems to be a suitable measure for safeguarding these 'crime hot spots' and is being used as a projection screen for fears and felt insecurities. Although an expansion of CCTV is mostly rejected in our study, CCTV measurement is seen as a suitable means to counter crime in particular spatial settings. The study indeed revealed many contradictions in the individual assessment of cameras in relation to actual knowledge and the meaning of these in relation to personal safety and spatial perception.
\end{abstract}

\section{Introduction}

The analysis of CCTV measures is often restrained to the uses and effectiveness of the technologies employed. The views and assessments of the ones that are the subjects of surveillance and their watchers in particular are far less an object of study. However, CCTV as a part of everyday life not only helps certain agencies to observe human behaviour, but also generates meaning by itself. The attitudes towards surveillance are not the outcome of certain measures itself - they do not follow from the installation of such technologies - but are embedded in general views on feelings of safety and spatial perceptions preceding these. Little empirical research has been conducted to explore the relationship between spatial perceptions, the general knowledge about surveillance technologies such as CCTV and individual attitudes towards these. Koskela (2002) has

\footnotetext{
${ }^{1}$ Insitute for Criminological Social Research, University of Hamburg, Germany. mailto:nils.zurawski@uni-hamburg.de
} 
undertaken some research on CCTV, gender and safety. Hölscher has done a small survey regarding CCTV and feelings of safety in Leipzig (2003). Helten and Fischer (2004) have conducted a study in Berlin shopping malls to research some of these issues. Klauser (2005a; 2005b) has also produced some interesting research about spatial appropriation and CCTV. This research here wants to further explore this issues and relationships.

Our study on which this article is based was aiming to understand the general knowledge that citizens of Hamburg have about CCTV set in relation to their general socio-spatial perceptions and imaginations of the city of Hamburg itself. We assumed that the level of knowledge about CCTV does not necessarily correspond to the meaning that is ascribed to the technology. Rather, that the basis for the latter lies in the socio-spatial perceptions they have about the city as a social space. CCTV adds just another possibility to channel these attitudes. Thus, the assessments thereof reflect the general views embedded in feelings of safety, fear or social preoccupations / prejudices that are assigned to CCTV as a means to control and overcome certain aspects of social unease. The meaning of CCTV measures has no direct correspondence to the knowledge that people actually have of it positively and negatively. CCTV seems to have become an end in its own - carrying certain promises that may conveniently be used to make up for an individual lack of control, fear or general uncertainty. There seems to be evidence that this also has a spatial component to it.

Two goals drove this study: first, to describe and analyse socio-spatial perceptions of people; and second, to investigate the knowledge, assessments and attitudes towards camera surveillance among the same people. Underlying these research goals was the idea, that those perceptions may provide leads regarding a more differentiated view of CCTV among people and eventually help to make statements about why people support or reject CCTV. We believe that CCTV as part of the 'real' world are incorporated into general 'worldviews' and are thus part of what Berger and Luckmann coined the social construction of reality (c.f.: Berger and Luckmann, 2003). The constructive quality of spaces is part of that general process. We define space as the result of mechanisms of production and appropriation. Space as such is not only defined by physical space, but also by social action and processes and the relational setting of social goods and human actors (Soja, 1989; Löw, 2001; Hubbard, 2002).

For the following analysis this article divides into three major parts. Part one explains the theoretical approach and empirical methodology used to gather and interpret the material, esp. the use of cognitive mapping for the analysis of the socio-spatial imaginations - the underlying background for the assessments concerning camera surveillance, i.e. the screen upon which attitudes and assessments are projected. This will be followed by an interpretation and discussion of the narrative interviews concentrating on the knowledge of and ascribed meaning towards CCTV. The final part of the analysis will be devoted to the spatial aspects of the study - employing cognitive mapping as a tool for data collection and interpretation. It will be argued that spatial dimensions do play a role in how the informants assess and view CCTV as a security measure and which meanings they ascribe to it. A short conclusion will round up the analysis and briefly discuss some of the consequences from the findings to put them into perspective. 


\section{Method and theory}

\section{Method: Spaces of research}

For our qualitative case study we selected two neighbourhoods in Hamburg representing two different, but characteristic environments (inner city and suburb) of the city. It should be noted that public, police controlled CCTV-systems were not in place in Hamburg at the time of our study, but were subsequently introduced in early 2006 (the interviews were made in 2004/2005). CCTV however had some impact on both quarters. St. Georg the inner city area - is hosting the main train station which is fully equipped with CCTV cameras, both inside as well as outside the premises. In addition the Hamburg subway system, run by the local transit authority (HHA) installed cameras on platforms and in trains over the past few years that were explicitly meant to monitor criminal behaviour such as vandalism, harassment of passengers or assaults. These were in operation at the time of research. As the main station was central to the rather small quarter (app. 10,000 residents) and provided some of the local shopping opportunities, CCTV was a relevant issue to most people living and working there. Lately there has been a discussion of implementing a CCTV system on the Hansaplatz, a central plaza in this neighbourhood. This was and still is met with much scepticism among the residents concerning the usefulness of the measure to counter problems in connection with drug related crimes.

St. Georg is characterised by a very mixed population and its central location in the city. Around Hamburg's main train station a major drug scene has developed over the years, which has been displaced by the stations use of CCTV and accompanying police measures. The residents are made up of a mixture of low and high income groups, a high percentage of migrants, working class residents that represent the 'old' St. Georg and young students. Seven mosques are located in this rather small neighbourhood alone. Among the more affluent residents we find parts of Hamburg's gay scene, making use of much of the revitalised higher income living spaces to the northwest of the quarter. St. Georg can be characterised as a mixed and open environment that in addition to its residents attracts high numbers of tourists and people from other parts of Hamburg, because of its lively pub and night-club scene.

The second area of study was a suburban environment located on the eastern city limits of Hamburg: a newly-built residential estate, named the Dorfanger Boberg (which proclaims itself "the village of the future" on a roadside billboard near the main access road). It is located in the larger administrative district of Lohbrügge with app. 4,000 inhabitants (i.e. the Dorfanger Boberg itself, with 740 units of single or town houses). For the Boberg estate video surveillance was planned to be installed as part of the initial development in the late 1990s. Parents should have been able to watch their kids on the playground from their kitchen via cable TV. However, unfitting with then current data protection laws, the plans were abandoned, though a substantial number of residents would still like to have the technology installed (which became clear from a residents group meeting we attended during the study). The estate offers affordable priced real estate for young families that enable them to buy their own home, but are otherwise hindered by the rather high prices in most other parts of Hamburg (cf. Bartels et al. 2001). Another reason for living in the Boberg estate was to get away from the city and its dangers, noise and unfriendliness often for the sake of their children, as was expressed by many of the interviewees. 
The choice of locations was made on the assumptions that residents of the two areas differ in their way of life, which would also manifest itself in the choice of the living environment.

In total we interviewed 41 people (17 female, 24 male), between the age of 22 and 69 (23 under 40 and 18 over the age of 40). These 41 people can be divided further into 4 groups that differ in their spatial relation to the research areas.

No. of respondents/location/type:

Boberg estate residents:

St. Georg residents:

St. Georg, police/security personnel: 11

St. Georg, non-residents/business 9

\section{Methods of research}

For the actual interviews we used a combination of two methods: The first part consisted of a variety of maps, which were used to gather spatial information on individual perceptions of the city. The second part was a structured qualitative interview on perceptions of the city, spatial aspects of safety and assessments of CCTV. In this article we are concentrating mainly on statements concerning CCTV. The objective here was to specify the peoples perceptions and knowledge regarding CCTV, and furthermore, whether and how they value possible benefits of CCTV. We were also investigating, if the particular knowledge about CCTV had any effects on their spatial or social behaviour.

In addition, the mappings generated yet more data that contributes to this analysis. Apart from free sketching mappings and maps that were investigating the social-spatial imaginations in a free manner - in form resembling the method developed by Kevin Lynch (1960) - eight maps were presented to the interviewees in which they were asked to state personal assessments on various items on a rating scale from 1 to 4 . The maps showed the borders of the 103 districts of the city of Hamburg. The items investigated were: feeling of security at night; feeling of security during the day; estimated crime rates; estimated density of police presence; estimated density of population and of migrant population in particular. They also had to map out their range of mobility on one map, indicating their frequency of movement, i.e. daily, weekly, monthly or a few times a year. On a last map the respondents had to indicate in which districts they would like to live or not live at all. In contrast to the other maps they only could use a binary rating scale (1 or 2$)$. The rationale behind this was to gather absolute statements, i.e. 'absolutely wanting to live' or 'under no circumstances.'

The form and design of the mapping methodology we employed have its roots in Geography, where it has also been used in spatial research on issues of spatial perception of safety. Generally, cognitive mapping has been developed in both Psychology and Behavioural Geography. The term as well and the methodologies used have undergone a variety of criticism and changes over the past decades (c.f. Kitchin and Freundschuh, 2000: Kitchin, 2000: 13; Kitchin and Blades, 2002). However, there is good reason to make use of this method for the investigation into socio-spatial imaginations regarding surveillance issues - as will be discussed analysing the maps developed from this data. 


\section{Cognitive mapping - theory and method}

The general function of cognitive mappings and cartographic representations of our environment is to reduce complexity and provide us with systems of orientation in space and society. Maps are therefore one of the most basic forms of human communication (cf. Short, 2003: 8). Ultimately, mapping is a means to control space and human behaviour, which unfolds a close affinity to surveillance in general (Dodge, 2005: 113) In making maps, humans do not only reveal something about their image of the world, but at the same time these artefacts refer back to its generators - us - and to the processes of its production (cf. Short, 2003: 24). Maps and mappings (cognitive and others) tell us equally much about who we are and what we do, as well as about the environment they represent. Maps do not only represent 'reality' but play an active role in the production of 'reality.' This holds especially true for cognitive representations of our physical and social environment that also shape our understanding of the world in a process of mutual interaction (Dodge, 2005. 114). Employing cognitive mapping as a method and approach expands Berger and Luckmann's concept of the social construction of reality - as they did not account for a spatial dimension within their theory (c.f. 2003: 29).

As a scientific method cognitive mapping has undergone much criticism and severe changes over the past 50 years or so. In essence cognitive mapping "concerns how we think about space and how those thoughts are used and reflected in human spatial behaviour" (c.f. Kitchin and Freundschuh, 2000:1).

Set in a broader perspective that acknowledges the social and cultural context cognitive mapping may also help to understand spatial dimensions of social imaginations - i.e. ideologies, perceptions and resultant provinces of meaning. The essential interest of the study of cognitive mappings is the possible prediction of spatial behaviour. This can be done by understanding how humans gather and process spatial and geographical information - information on which later decisions are based. Although these geographical perspectives seem to have limits to answer questions concerning the wider field of socio-spatial imaginations, the roots of the methods and the possibilities of application for research can be found within. Various approaches developed in the field of Geography (c.f. Kitchin and Blades, 2002: 11ff) provide interesting aspects of access to make use of the general approach of cognitive mapping for our research -especially those that highlight the role of knowledge and the social and cultural contexts in acquiring this knowledge and the attitudes based thereupon. Less concerned with decision-making, we wanted to investigate the connections between socio-spatial imaginations, knowledge of surveillance measures and the attitudes towards these in every day life.

Jameson (1991; 1995), who has employed cognitive mapping as a theoretical concept beyond the limits of geographical uses, defines it as a way "to see in the cultural logic and forms of postmodernism an instrumental cartography of power and social control" - a way of seeing how space hides consequences from us (c.f. also Soja, 1989: 62f). The totality of the global, which the individual may not experience in all its aspects, may be thought and represented through the process of cognitive mapping. The process enables the individual to relate to the world as a whole, to find a place and location as part of a totality. 
Many of these representation that are used to formulate this kind of locality are based on ideas, metaphors, imaginations (e.g. of geography and society) and are themselves expressions of simplifications, stereotypes, attitudes and patterns of orientations. They can be thought of as the socio-cognitive images of a society - supplementing Berger and Luckmann's ideas concerning the social construction of reality. In a way their use of the term routines (Berger and Luckmann, 2003: 26, 56f) seems to be corresponding to the systems of orientation that can be found in cognitive mappings. These routines enables the individual to act without constant doubts, which leads to a habitualisation and hence orientation. Individual knowledge will be transformed into collective, social knowledge by way of producing general systems of relevance that include the self and the other (c.f. Schütz, 1971: 13ff). For Berger and Luckmann this is the basis to construct „reality“, which for the individual lies beyond the self, but has an objective meaning. This objectified meaning constitutes the social, through which social control and collective institutions such as law systems become possible and predictable (c.f. Berger and Luckmann, 2003: 78f). In effect cognitive mappings are part of these constructions, reflecting and representing reality.

As it becomes clear that maps and the process of its production have a lot to do with control and knowledge, it can be concluded that these processes may also be linked to discourses of surveillance and its practices. In regard to the presented research, it should be noted that we too were constructing certain spaces, in that we were presenting precast maps to our informants that were representing the 103 districts of Hamburg. Thereby we were preconditioning the imaginable space and took control of a possible spectrum of answers in a bounded spatial setting. To empirically research these socio-spatial imaginations, we had to get back to the more quantitative mapping methods that were used to accompany the qualitative interviews and were taken as part of a bigger phenomenological approach. The graphic maps that were the outcome of this research must not be seen as self-sufficient, but as part of a broader approach to analyse sociospatial imaginations in the context of CCTV and its surrounding discourses of safety, security, surveillance and constructions of reality. Some aspects of these discourses and the constructions that emanate from these interviews will be discussed first, before these will be discussed as part of the informants' spatial context.

\section{Assessments of CCTV}

In the interviews the informants provided answers towards CCTV, which display some of the general attitudes towards this measure. We are focusing here on their knowledge of the technology and the meanings that they ascribed to it. The succeeding spatial analysis helps to put these statements into a wider perspective that suggests a strong interdependence between spatial constructions and attitudes towards surveillance. We will look at selected aspects of the interviews, namely at how the informants link CCTV to crime. In this regard we will discuss their perception of CCTV as a measure against crime and their assessments regarding the assumed aims of public cameras surveillance. Finally we will examine the term 'crime hot spot' which seems to have a close relation to CCTV and its discourses. 


\section{CCTV and its attachment to crime}

Nearly all of our informants assumed that CCTV has been applied mainly for crime reduction. Other objectives, e.g. the regulation of work routines, saving on police personnel or assistance in accidents were rarely mentioned. Thus, their assessments of CCTV revolve around such terms as 'crime' or 'criminals'. These terms were used in a broad and unspecified sense to identify a rather amorphous, not clearly defined population. They often referred to 'crime' even though they only meant minor regulatory offences. Regarding criminal behaviour, the views of the respondents became ever more abstract and complexity seemed to be reduced. All of them named at least one of the following punishable acts, which they perceived to be threatening: abuse of drugs accompanied by drug-related crime, theft, violent acts and burglary. Unsurprisingly, these are all offences that were part of public discourses around CCTV in Hamburg. However, the importance that they receive through these public debates is by no means justified by the frequency of their actual occurrence. Crime as we can see here is not a fixed, well-defined fact (c.f. Hess and Scheerer, 2004: 73). Not everything that has been deemed a criminal act by the informants is criminal in the legal sense.

In addition, many informants believed that there is a higher probability of becoming a victim of crime because of an alleged increase in crime. At the same time many of them thought that formal social control was decreasing. The prime indication of this was for them the low profile of police officers at public accessible places while they stated a rise in fringe group members such as 'beggars,' 'dossers,' 'junkies' or 'prowlers.' Nearly one third of the informants were asking for a change of this situation - cameras ranked high among the measures that were thought to bring about these changes. However they rarely questioned these measures regarding its actual success or possible infringements on their personal lives. Consequently justifications of cameras surfaced in statements like "better than nothing" or "it can't be bad". The wish for change seemed to be so strong that any possible side effect was suppressed. Surprisingly, persons who assessed the entire situation as not as threatening, proposed the same arguments. Unpleasant aspects were frequently suppressed and much place is granted for symbolical actions: "Why should there be a misuse of CCTV. It has been shown that CCTV works" (interview) ${ }^{2}$. At the same time the responsibility for varying actions is personalised and delegated to institutions, foremost to security personnel or the police, which represent highly trusted agencies. The police was generally deemed responsible for the operation and control of the cameras in general without making any differentiation concerning different CCTV systems. A European Union survey from 2003 revealed that $75 \%$ of all Germans stated to have absolute confidence in the police handling with data (European Opinion Research Group 2003: 21, 73). Possible side effects such as misuse of data did not play a major part in their thinking. Many informants stated this confidence and overestimated the role of the police at the implementation of CCTV: "the police are responsible for CCTV and therefore I have confidence with it” (interview).

2 All citations labelled 'interview' are taken from the interviews conducted between May 2004 and January 2005 


\section{Suspicion and data protection}

14 informants underlined that CCTV has nothing to do with them by stating: "I do not have anything to hide." In reverse this means that there are persons that may have something to hide - which again would justify the cameras and generate exclusion of these very people. In consequence everyone in the range of the cameras is constantly reminded of alleged dangers that can be assigned to certain people or groups. CCTV is attributed with inherent qualities of social sorting, against the fact that the cameras itself non-discriminatory capture everything in their range. Critics of CCTV remind us that this puts everyone under a general suspicion of being a potential offender (c.f. Leopold, 2004: 35). Our informants however do not see themselves subject to a general suspicion. In their view the cameras are only concerned with groups of people to whom they do not belong. Altogether only 12 persons mentioned the possibility of abuse by video monitoring and just six of them described this as a menace and asked for more transparency (c.f. Reuband, 2001:9, with similar results in a study in Dresden and Düsseldorf). A root cause for this seems to be lying in the low knowledge concerning civil liberties. In the European Union survey only $23 \%$ of the Germans stated, that they are aware of data protection organisations. And only 21\% knew of the existence of data protection laws (European Opinion Research Group, 2003: 21, 73). But if these persons know only little about the law that grants them the "right to informational self-determination," they will also be unable to see that public video surveillance may infringe upon this very right. Our survey suggests that this seems to be the case with our informants. Data protection as well as unspecified possibilities of abuse regarding CCTV were brought forward only by few informants, and then only in a rather brief and cursory manner.

\section{Assumed a ims of C CTV}

Risk calculation plays an increasingly important role for attitudes towards CCTV. Camera surveillance offers the possibility to transfer risk considerations onto space. CCTV can be used as a suitable policy instrument, which replaces social security by physical security, while the supposedly menacing elements are excluded (Wehrheim, 2002:45). The main arguments by the proponents of CCTV in the public discourse primarily centre on an aspiration for a decrease in crime rates and the rise of feelings of safety among citizens. The strategic vehicle through which this wants to be achieved is prevention concepts. The question is to what extent these official discourses expand into the provinces of meaning and the everyday lives of the informants? What impact do they have on their assessments of CCTV as a security enhancing measure?

Asking only for a general assessment of the efficiency of CCTV, we tried to avoid preconditioning possible answers. However, many informants talked at their own initiative about issues such as crime prevention and public safety. Their appraisal of CCTV depends on the extent in which risk calculations and cost-benefit calculations impact on their behaviour. These aspects impact directly on both, the attitudes towards prevention approaches and on their perceived feelings of safety. We will discuss each of these aspects below.

\section{a. Prevention}

27 informants state prevention as an important aim of CCTV. All of them equate prevention with deterrence. Risk calculations, the consideration of costs and benefits and 
the assessment of a possible prevention or deterrence effect by CCTV are interdependent. The more the informants' considerations were lead by risk calculation, the more a preventive effect of CCTV is implicated. Whether there is such an effect or not was considered differently. One third assumed a strong effect, one third said that there is no deterring effect and one third said that it depends on the entire situation.

\section{b. Less crime}

29 respondents mentioned repression as an assumed aim. Nearly all of them believed that CCTV aims at prosecution of offenders. At the same time only a few of them believed that CCTV contributes to a decrease of crime rates at camera-equipped places. This is a significant contradiction, which is reinforced by those informants, who believe in deterrence and rational choice of potential offenders, an aspect that should lead to decreasing crime rates. Furthermore 11 persons believed that employing CCTV merely results in displacement.

\section{c. Perceived feelings of safety}

33 interviewees mentioned the enhancement of feelings of safety as one of the aims of CCTV. Their assessments differed depending on, whether their own feelings of safety improved by CCTV or not. A narrow majority affirmed that their feelings improved through cameras. The statements of these respondents indicated that the term 'feeling of safety' is used in a subjective manner and a variety of ways. The statements were also highly related to crime rates, which suggests that some informants seem to have transferred general fears and uncertainties towards crime. Several manifestations of social disorder (graffiti, trash on the street, groups of young people) are reinterpreted as being criminal offences. Some respondents even classified behaviour patterns and attitudes as being on this level. Consequently the term 'crime rate' is proven to be the result of a process of social judgement, "People become just more aggressive. If somebody bumped or one bumps into somebody by mistake he gets hit on immediately. So there is more and more crime on a low level.” (interview)

\section{The public discourse}

The frequent use of catchwords used in the public discourse on CCTV indicates that these have a strong influence on the informants' attitudes. Aspects that are not identified as being a central theme in the public debate do rarely appear in the interviews. Only few respondents were articulating their discomfort regarding CCTV and data protection issues as well as the possible abuses of technology or selective observation. The potential spatial spreading of CCTV as an inherent quality was not mentioned at all.

On the other hand, those aspects and arguments that were identified as being central, appeared in almost all interviews, as there were: prevention and deterrence, crime reduction and the enhancement of feelings of safety. Consequently, places at which CCTV was deemed necessary as a means to counter the ill effects of crime and lack of safety were often referred to as 'crime hot spots.'

'Crime hot spots'

All of the informants, who used the term 'crime hot spot,' used it in a widespread context but without a clear definition - often even without concrete local reference. This illustrates the reduction of social problems onto a spatial context. Thereby criminal 
offences are separated from individuals and a transmission is facilitated into certain areas, which are then attributed as "highly crime-ridden." An unreflecting acceptance of the image of the "crime hot spot" leads to a spreading of the very same patterns that were used to identify these spaces in the first place - detached from any empirical facts or individual knowledge: "If it is a crime hot spot it must be, because they said so" (interview). In general, the majority of the informants looked upon CCTV favourably at high frequented places, in which many different social groupings were mixing, e.g.: trainstations. It is mainly at such places that situations perceived to be unsettling do occur. Some informants said that cameras can provide for a relief of behavioural decisions. They may also help to reduce complex, difficult and unpleasant situations by the implicit disciplinary effect through cameras in monitored areas. Should these situations appear nonetheless, several respondents felt that it would not be necessary to intervene in order to dissolve these situations because these were documented by cameras anyway. 19 respondents spoke out in favour of either or both of these aspects.

Ultimately, most of the informants supporting CCTV favoured cameras at places they refer to as 'crime hot spots.' However, almost none of them is in favour of an area-wide implementation of CCTV. In contrast to these rather distinct opinions regarding CCTV, most informants could name few places with CCTV in Hamburg, although all of them had an opinion whether there should be more or indeed less cameras in the city in the future. Therefore, the evaluation concerning the support or rejection of cameras, must take into account that answers were differing and indeed contradicting each other, if either asked for attitudes towards the technology in general or concrete situations and respective behaviour patterns.

\section{Spatial aspects of safety, insec unity and CCTV}

As it becomes clear from the above analysis, many statements do refer to spatial aspects or are indeed spatially driven, e.g. in respect to the notion of 'crime hot spots' and surrounding arguments. Looking at the informants' cognitive mappings of the city in respect to safety and mobility range may underline some of the points made.

We argued that knowledge is influenced by experiences - so are the imaginations the informants have about the city of Hamburg itself. One of the main aspects in their reasoning for or against CCTV was the individual feeling of safety. Its enhancement was either mentioned as an assumed aim of the agencies installing the cameras, or as part of their personal wish of what the cameras could actually achieve. Using particular mapping methods we tried to make sense of the spatial patterns and perceptions in relation to specific items. Although we presented them with a bounded spatial environment, the results display rather different views of Hamburg which represent different constructions of space that also lead to diverse consequences. The maps presented here can be seen as the visual displays of the provinces of meaning or cognitive mappings that where in part verbally expressed in the narrative interviews.

One of our basic assumptions was that motivation for surveillance or its support by citizens relates to their personal imaginations of space - social and physical. This, we 
assumed, has bears a relation with where and how they live and move in a city. The informants' assessments of CCTV proved to be very contradictory, depending on the given context of the cameras. The mappings will help to put these statements into a wider spatial perspective, in the following case in regard to personal mobility and safety.

\section{Mapping socio-spatial imaginations}

For the discussion here, we will concentrate on selected items and their according maps. The items that will be looked at are: felt safety and perceived crime levels. Maps displaying the range of mobility serve as background to these perceptions. In using these maps of aggregated data on the mobility range of residents from St. Georg ( $n=9)$ and the Boberg estate $(n=12)$, we will analyse the impact of spatial perception on the possible construction of imaginary spaces.

The first two maps represent the range of mobility of the respective residents of the two neighbourhoods.

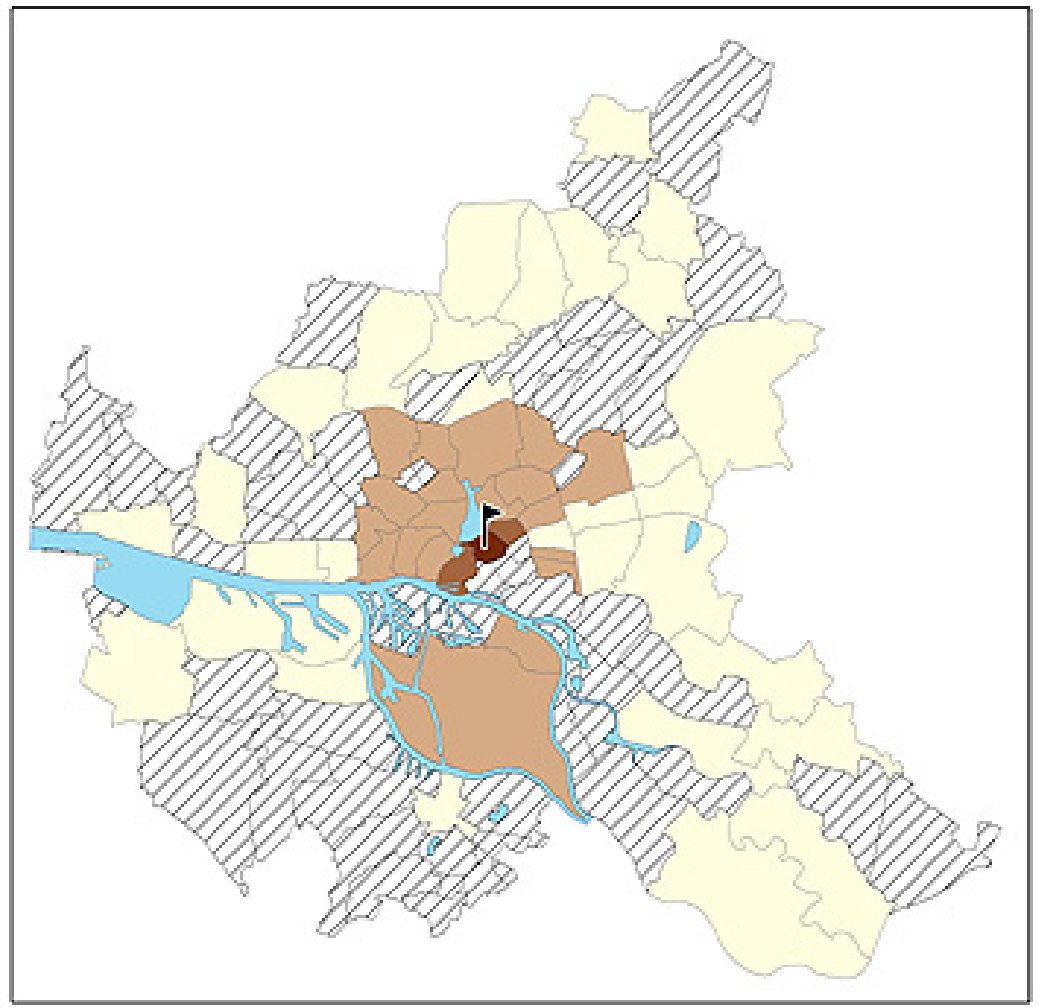

Hamburg range of mobility frequency of stay

Group: St.Georq residents

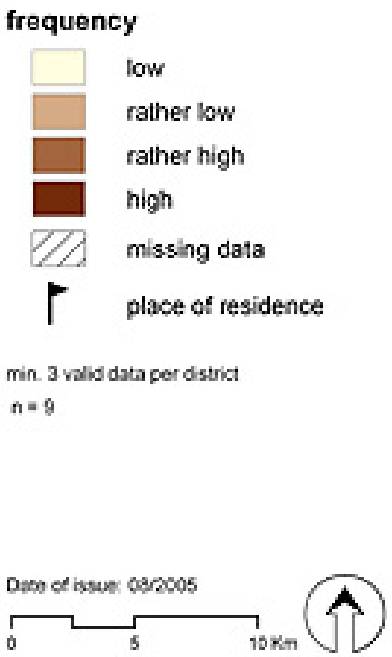

Map 1: St. Georg - range of mobility 


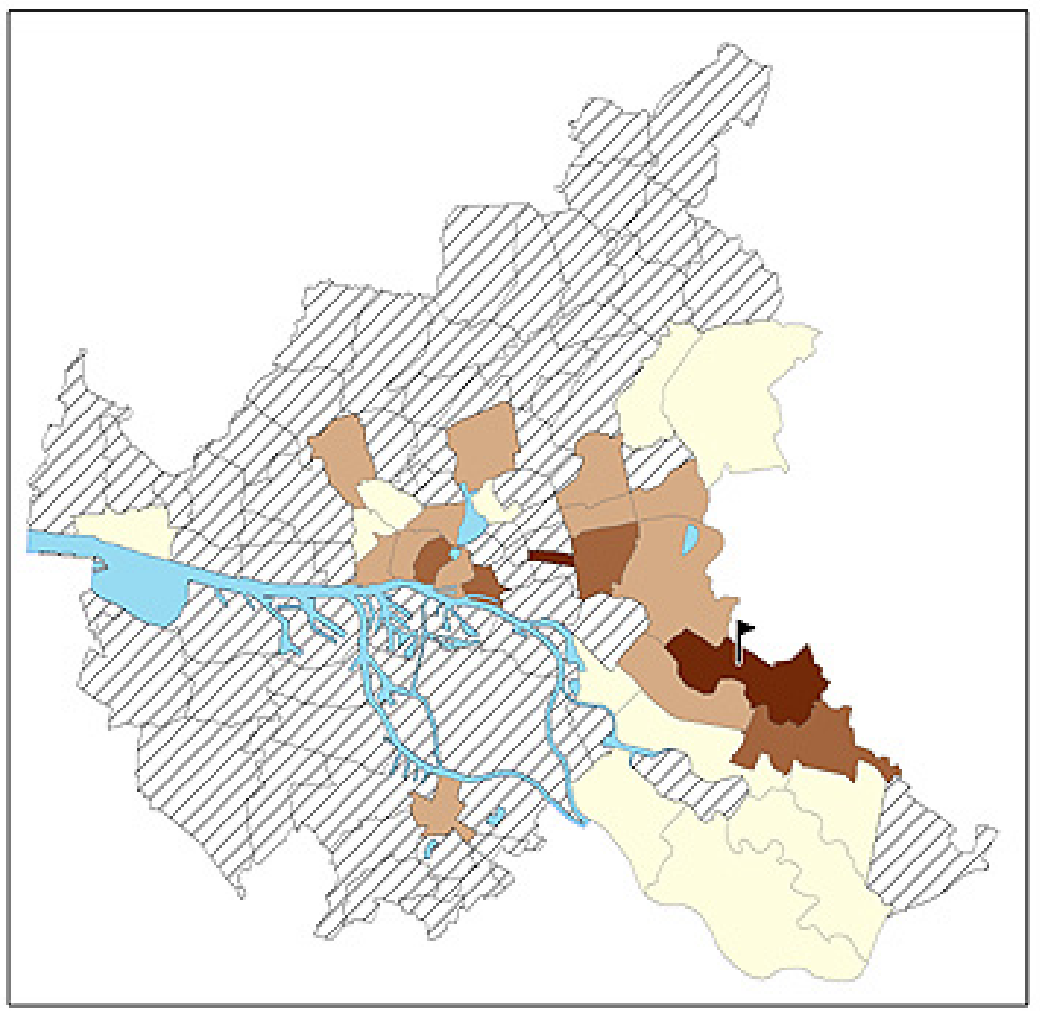

\section{Hamburg}

range of mobility

frequency of stay

Group: Boberq residents

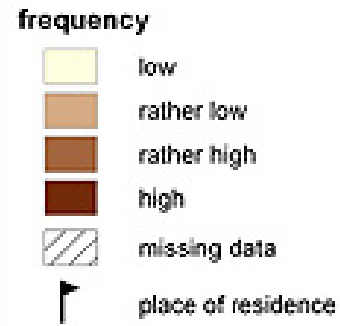

min. 3 valid data per district

$n=12$

Map 2: Boberg- range of mobility

Two distinctive patterns become visible. St. Georg and Boberg represent the core of each map accordingly (little flag). The depth of the colour indicates a higher frequency of movement or stay in this area. The second map shows a slightly more scattered allocation of higher mobility, which can be explained by the difference between workplace and residential location of the Boberg informants. Overall we can see a wider mobility range of low frequency in the first map that covers many different areas of the city, while in the second these are situated much closer to the place of residence and are smaller overall. Many of the residents of St. Georg do not only live, but also work in the neighbourhood or close by. This as well as other forms of movement are also facilitated by easy access to public transport, which in this part has a high network density. Residents of St. Georg seem to know more of the city and have a wider range of mobility, although their centre of presence remains the neighbourhood itself. Given that it is an inner-city district, almost all leisure opportunities, shops, service facilities and also workplaces can be reached with public transportation or are in walking distance. Their range of mobility for most aspects of their lives is rather short - however they do move considerably to other places, even only a few times a year. The people from the Boberg estate remain predominantly in the eastern part of the city. 


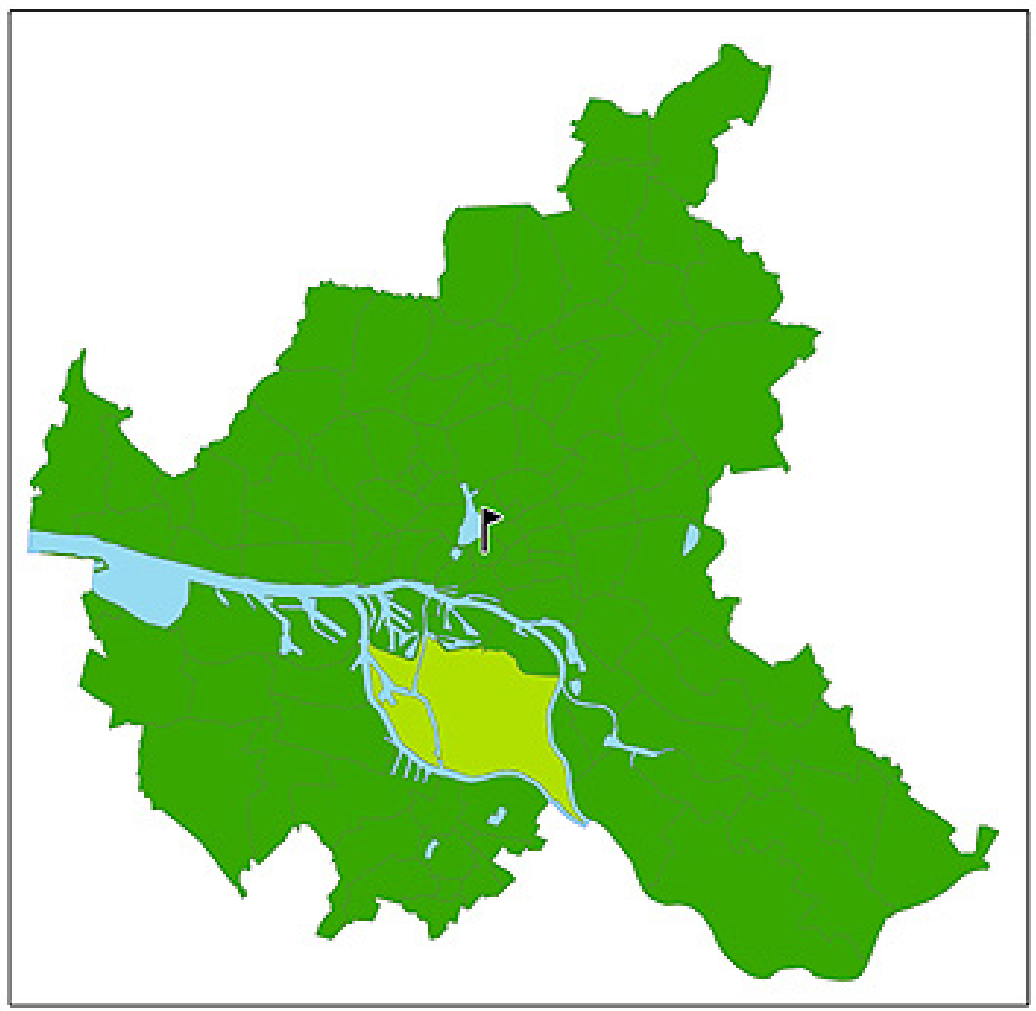

\section{Hamburg}

feeling of safety

at daytime

Group: St.Georg residents

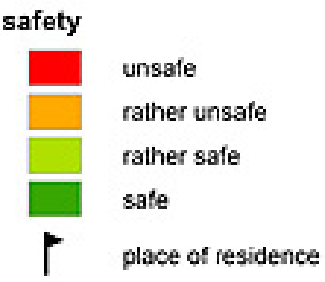

min. 3 valis deta por district

$n=9$

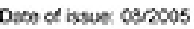

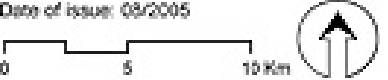

Map 3: St. Georg - sa fety during daytime

Astonishingly the respondents from St. Georg deemed almost all parts and districts of Hamburg as safe places to go at daytime. The only exception is the district of Wilhelmsburg, located south of Hamburg's port, were they feel a little less than absolutely safe. This surely accounts for the rather bad reputation of the districts itself, with a high rate of migrants, old industrial architecture and low social structure - despite its actual crime rate that lies below the city's average. Its bad reputation among the citizens of Hamburg in general has not been validated by these respondents as we expected. Quite differently from the answers given by the group from Boberg. 


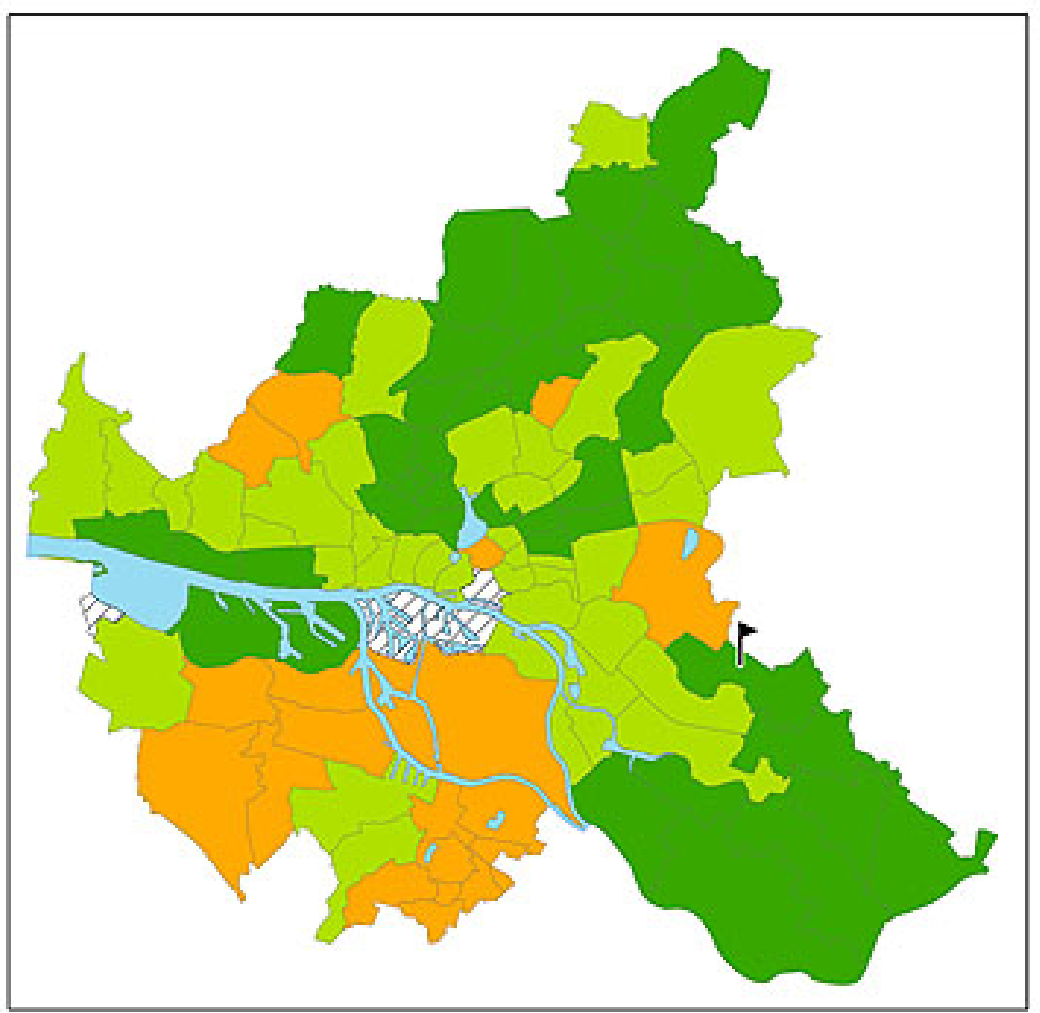

\section{Hamburg}

feeling of safety

at daytime

Group: Boberg residents

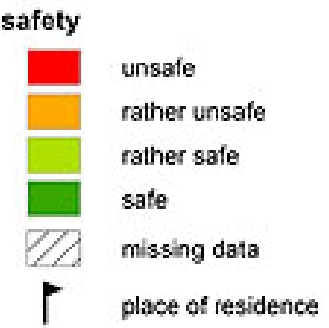

min. 3 valis data per dstrict

$n=12$

Map 4: Boberg - safety duning daytime

The areas of absolute safety are much smaller and cover some of the more affluent residential areas towards the edges in the north and west on the river Elbe, as well as to the south-east, the latter characterised by a low population density and an agricultural environment. South of the river, including Wilhelmsburg and some isolated enclaves throughout Hamburg are deemed to be unsafe during daytime. This is striking, as most of these areas do not fall into the range of mobility of the respondents (see map 2).

The feeling of safety at night time (maps 5 and 6) looks quite similar: St. Georg residents show almost no unease with any part of the city, while their suburban counterparts see a different city altogether. Although certain areas are named by both groups as being unsafe, the St. Georg residents were still stating a feeling of safety rather than not. Most unsafe areas named by Boberg residents however are located outside their own range of mobility. The differences in perception are indeed striking and represent two different cities all together - pointing towards a construction of spaces and the impact of imagination meaning in regard to social contexts. 


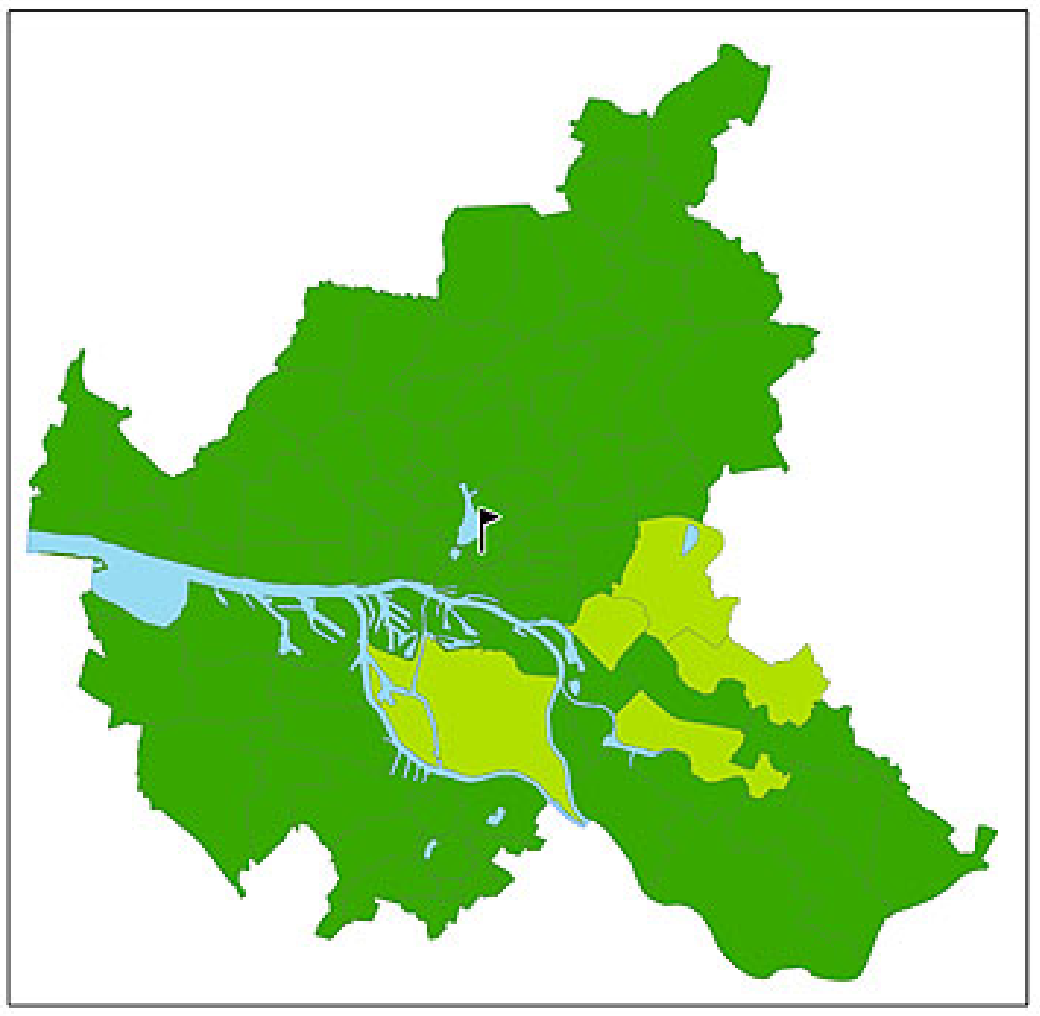

\section{Hamburg \\ feeling of safety \\ at nighttime}

Group: St.Georg residents

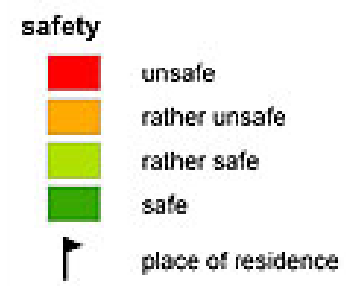

min. 9 valis data per district

$n=9$

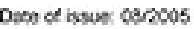

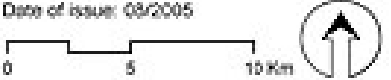

Map 5: St. Georg - safety at night

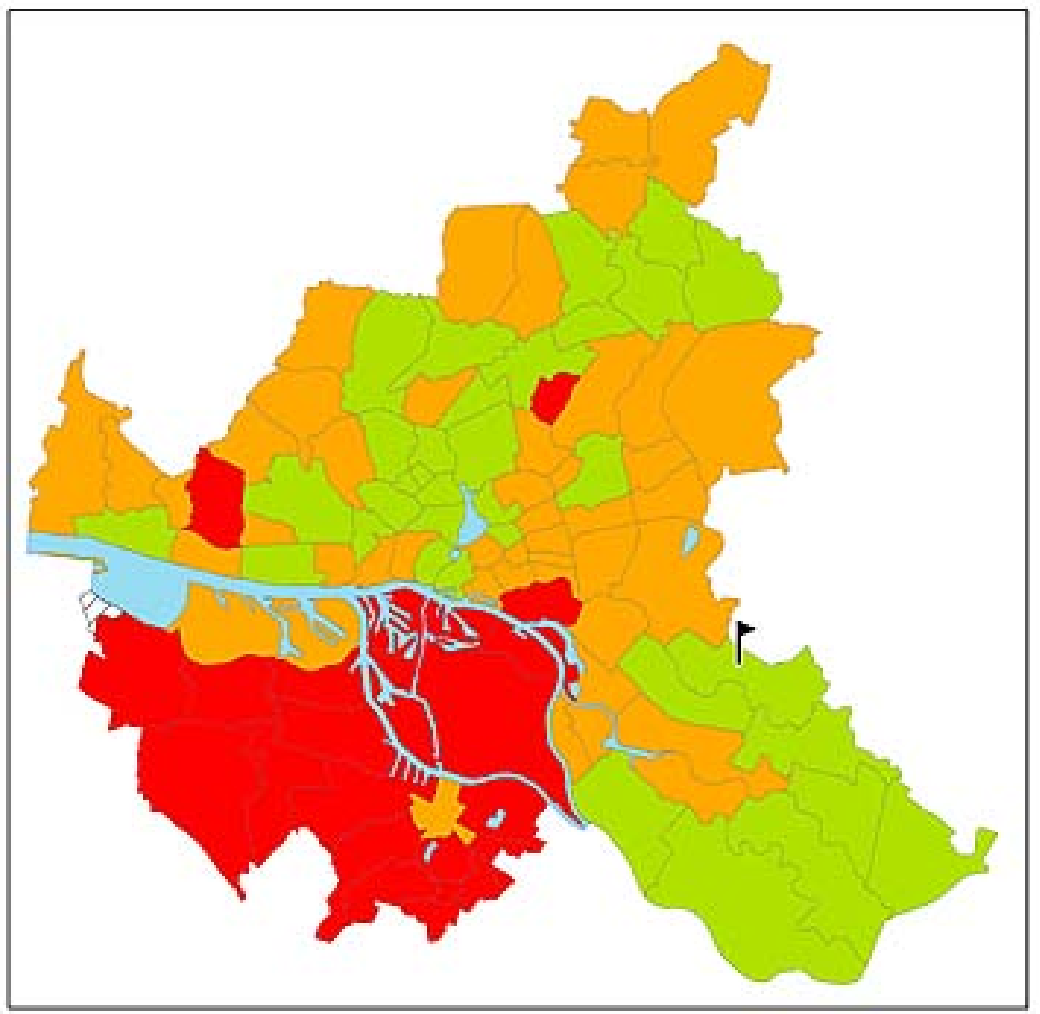

Hamburg

feeling of safety

at nighttime

Group: Boberg residents

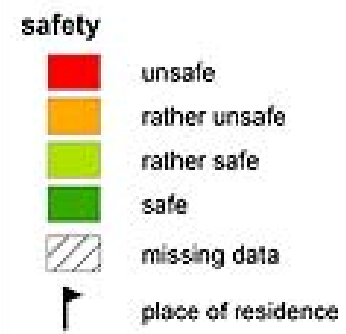

min. 3 valis data per district

$n=12$

Deno ef issun oarsos

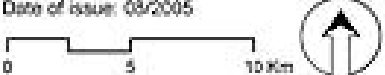

Map 6: Boberg - safety at night 
These perceptions reveal parts of an imaginary geography of Hamburg, which is also reflected in the perception of crime. Maps 7 \& 8 show only little differences, with only three areas marked as having a high crime rate by Boberg residents. Among them St. Georg, which indeed has an above average rate (1605/ Hamburg average: 157, Stat. LA HH 2003).

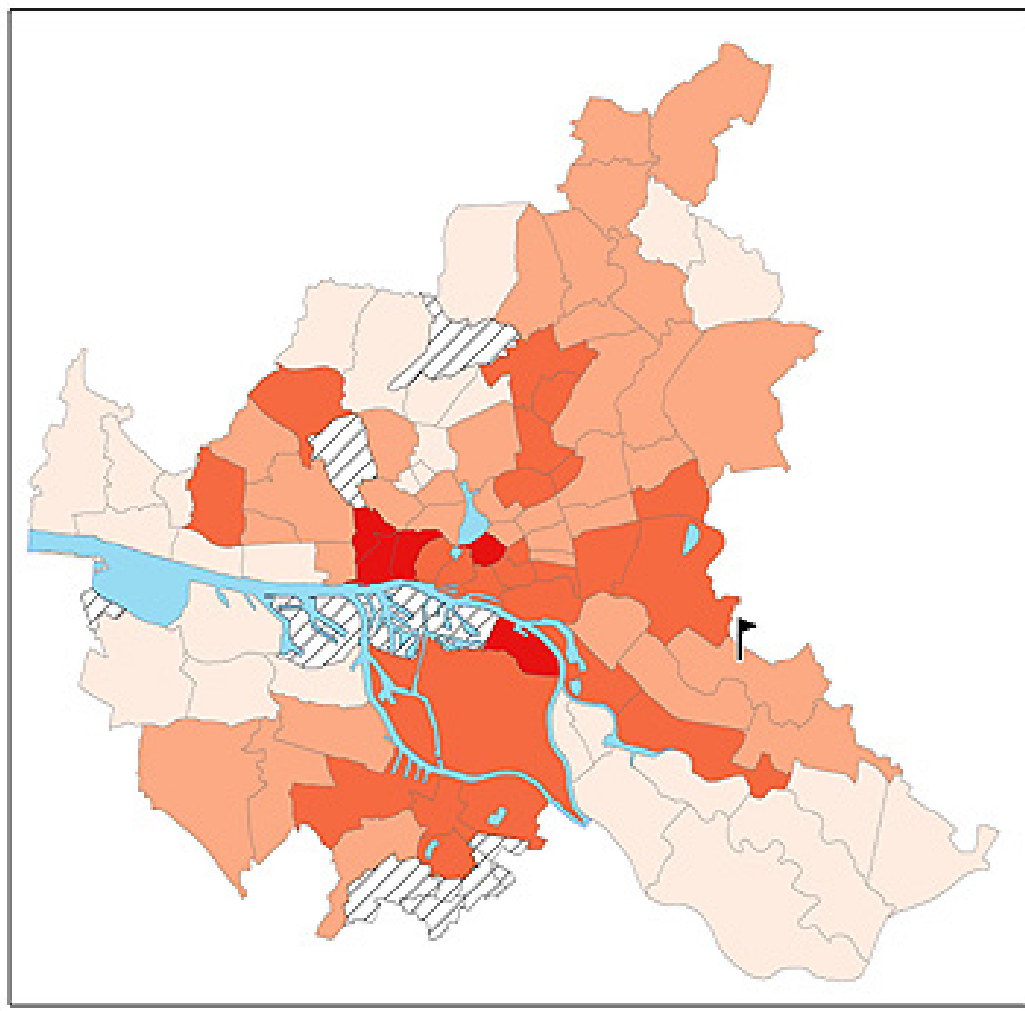

\section{Hamburg} perceived crime rate

Group: Boherg residents

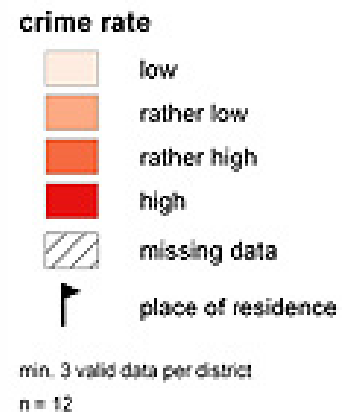

Map 7: Boberg - perceived crime rate

St. Georg residents assessments display a similar picture, but with less extreme mentions. The district of St. Georg itself is also rated as having a rather high crime rate, which is contradicting the earlier notion that its residents do not feel unsafe in the area itself as indeed nowhere in Hamburg.

The displayed maps reveal obvious discrepancies in the spatial perceptions concerning issues of safety and crime rates. The data alludes to a process of reality construction that is represented in the displayed socio-spatial perceptions. Although the sample is small, the maps do have some merit, not least because the informants were chosen at random, are vaguely representing the two resident groups and show obvious differences that are not merely coincidental. Thus, these maps do represent parts of the socio-spatial imaginations of our informants. Albeit, these maps are only a vehicle to visualise imaginations and perceptions of the informants - they are not the complete cognitive mapping itself. Together with the statements from the interviews they display a more differentiated picture of how space is constructed, perceived and negotiated. 


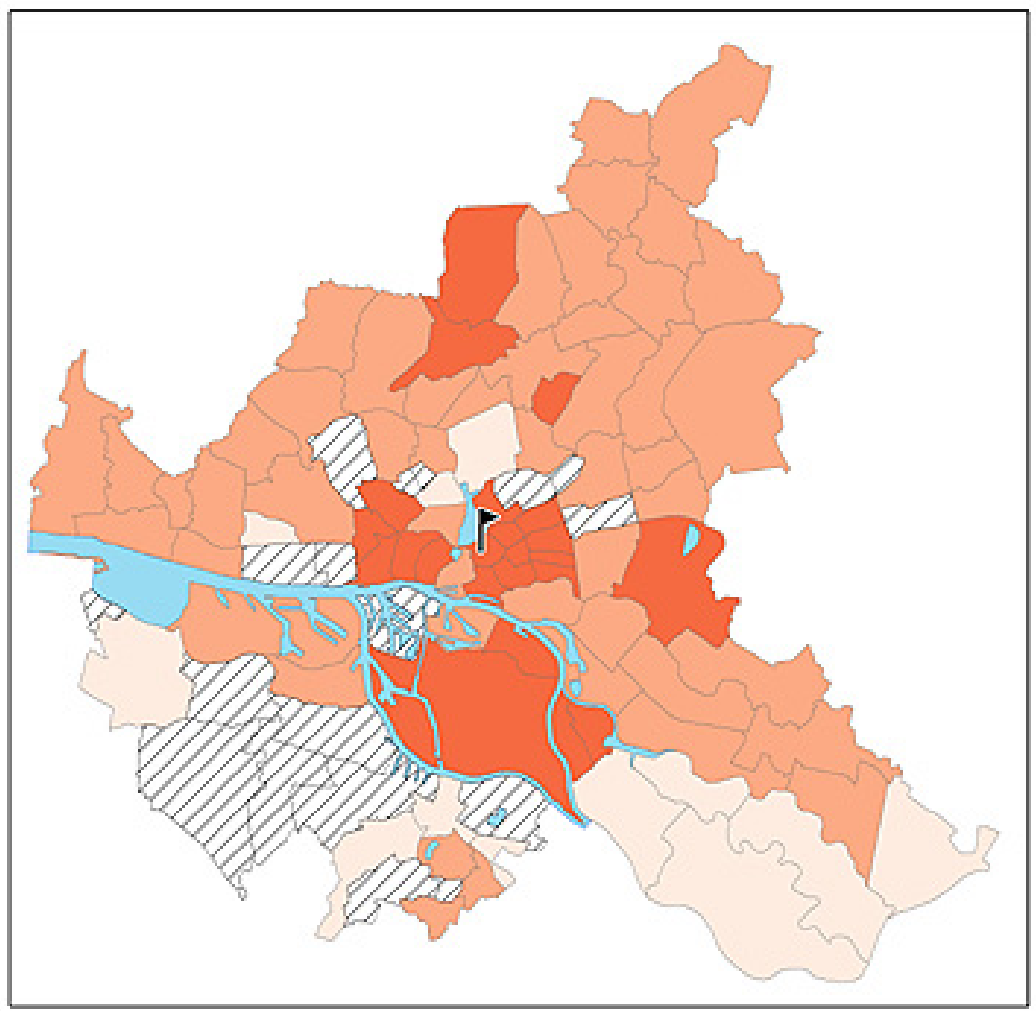

\section{Hamburg}

perceived crime rate

Group: St.Georg residents

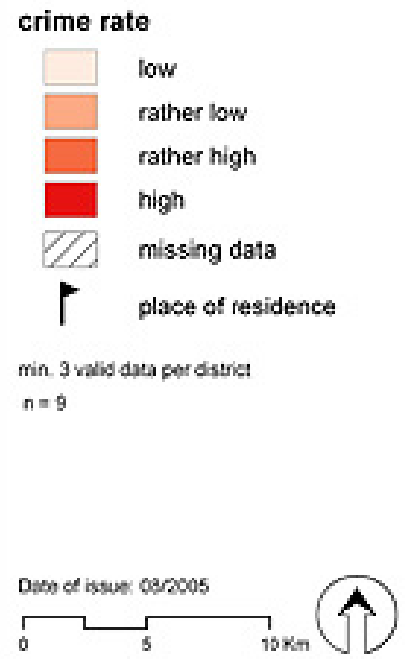

Map 8: St. Georg - perceived crime rate

\section{Conclusions}

As we have shown in the analysis of the narrative interviews, the general knowledge about CCTV is low and may often be imperfect. The degree of rejection or support does not seem to depend on the level of knowledge itself, but is also dependent on the meaning that CCTV has been ascribed to. Uses and effects of CCTV seem to have been simplified to fit into the routines of everyday lives (Berger and Luckmann, 2003; Schetsche, 2000) and into the general socio-spatial imaginations that precede these. Aspects such as age, gender, or social status do not seem to influence the outcome of the mappings as much as the place of residence does. Compared with the general attitude toward CCTV - support or rejection - it shows that the perceptions stated in the maps do correspond. Boberg respondents are rather in support of CCTV, while the St. Georg respondents are more likely to reject such measures.

The results are consistent with our theoretical expectations and relate positively to the maps on perceived safety and mobility above. The residents of the Boberg estate seem to be more in favour of CCTV than their inner-city counterparts.

From both parts of the analysis a few conclusion can be drawn that highlight the relation of spatial perceptions, social imagination and the meaning of CCTV among the informants. In the first part we argued that crime itself is a constructed item, which was perceived differently by our informants. It was used as an umbrella definition which 
included criminal activities as well as incivilities and other minor irritations. CCTV was seen as a measure to tackle crime in general without clear reference to any special form or kind. How this was to be achieved - whether through preventive or repressive effects remained unclear. What became clear was that crime was related to particular spaces, namely to so called 'crime hot spots', and that it was at those places that CCTV was felt to be of meaning to tackle crime. The constructive character of such 'crime hot spots' was obvious, although rarely a concrete location was named. CCTV itself was part of this construction, i.e.: CCTV was as much a measure to tackle problems at these places as it was a marker of such hot spots in the first place. In addition, CCTV was seen as having selective quantities - forms of social sorting were ascribed to the technology and the strategies behind the cameras. The statements that mentioned distinctive groups as being the actual targets of CCTV without considering that cameras are indeed controlling a given space, made it clear that certain ideas and wishes were assigned to that measure. What the narrative interviews did not reveal however, were the socio-spatial imaginations of the informants regarding their general perceptions of space in respect to safety and crime. These on the other hand are the basis onto which arguments about CCTV were built. In that sense, with the maps we are taking a step back to look at some preconditions for the arguments made.

Despite having a rather small overall range of mobility, the informants from the both neighbourhoods provide a rather differentiated image of the city concerning their perceptions and feelings on safety and crime rates. It seems obvious that most of their perceptions are not based on personal experiences. The maps are a reflection of their cognitive mappings, their imaginary social and political geographies of the city. The perceptions of places as safe or unsafe differ considerably - but not so much their assessments of crime rates in the city's various districts. Looking at the level of support for CCTV measures, a further difference surfaces. CCTV as a measure against crime seems not to be bound to the perception of crime itself, but rather to feelings of safety and an emotional proximity to a given space. While St. Georg residents see their own neighbourhood as having a high crime rate, CCTV is not the option of their choice to tackle the problem in the first place. In reverse the Boberg estate residents would not go to places with a high crime rate - or indeed avoid them already - but are all in support of CCTV as a measure against crime. But if CCTV not only tackles crime, but also is an indicator of crime itself, it seems unlikely that these informants would expand their range of mobility to these places even if CCTV would be in operation. The meaning ascribed to CCTV is one of control of certain spaces and groups of people - a screen onto which their own feelings of safety, unease and imaginations of a certain locality were projected. This leads to a second conclusion, involving their socio-spatial imaginations in the sense that Jameson (1992, 1995) was describing cognitive mapping as a process that enables the individual to relate to the world as a whole, to find a place and location as part of a totality. Comparing the two groups two distinct patterns emerge. Boberg residents display a binary, oppositional perception of the city, while our informants from St. Georg gave a much more inclusive picture of 'their' city.

Living in a rather safe suburban environment, the feelings of insecurity among our Boberg informants seem somewhat incomprehensible. But on the other hand, without personal experiences of the districts they have to rely on secondary information, rumours and general images of certain places and localities. The city - i.e.: urban life in places like 
St. Georg - may be perceived to be somewhat alien of which they do not want to be a part. They want to be detached from it, especially from the 'dangers' that they perceive to be part of it. If these maps represent patterns of orientation, it may be concluded that the world outside their own personal and more intimate environment - the Boberg estate and some other places - is largely unknown, alien and even dangerous. Hence, the mappings also suggest a social or cultural separation of them and us, where 'them' is a largely unknown entity. The support of surveillance seems consequential in that it offers a screen for projection of any kind of unease or insecurity. With CCTV the unknown is controlled by trusted agencies such as the police, as it is 'the others'/'them' that are subject to CCTV and not they themselves.

Although our St. Georg informants' range of mobility for the most part is restricted to their very own neighbourhood, their perception of the city and its spaces concerning the feeling of safety are very dissimilar. Located in the heart of Hamburg, St. Georg is perceived to be in the city. It does have many inner-city problems, but also a close-knit communal structure - like community workshops, clubs and other activities that make for a vivid neighbourhood culture. Confronted with a variety of different cultures, social groups and problems as well as the commitment to live in an inner-city, they seem to be more a part of urban live than their counterparts from Boberg. They are of the city and seem to have developed a more inclusive sense of the world around them, of which in many cases they do not have a personal knowledge either. The latter does not seem to affect their feeling of safety in other parts of the city.

Although both groups named similar districts as having a high crime rate, it does not affect the feeling of safety among the St. Georg informants, nor their wish for more control. Basically the two groups seem to differ considerably in their cognitive mappings towards a social totality, whereby the Boberg residents represent a more exclusive 'us or them' model, while the St. Georg group can be described by a more inclusive one. As surveillance can be viewed as being part of the process of cognitive mapping in order to gain control of the unknown, to map and to scrutinise the process of orientation, it is not surprising to find a higher level of support for CCTV among the Boberg group.

From the analysis presented in this paper it became clear that methods of mapping can be a useful tool in studying issues of surveillance at a very basic level. Although we operated with a small sample, some of the results showed that the use of the methodology employed as part of a qualitative approach provides us with material with which we can study surveillance issues from different perspectives. Mapping socio-cognitive representations of space or spatial imaginations that become 'reality' and consequential for its bearers has proved to be a valuable way to research some of the underlying narratives that affect attitudes and strategies of surveillance. The various mappings presented in this paper are only an extract of cognitive mappings regarding images of space and safety. 
To sum up the findings:

- The meaning ascribed to CCTV does not depend on the knowledge of it.

- Our informants assign a variety of tasks to the cameras, mostly in relation to crime and the deterrence of crime.

- CCTV is becoming a signifier of crime for some people, marking space where cameras appear as potentially unsafe.

- Crime becomes spatialised, while CCTV is believed to be selective - watching some and leaving others out.

- CCTV is seen (or hoped for) to be an instrument of social control. Aspects of social sorting do play into these arguments.

- Rather it seems, that the selective process is something that is being projected on to the cameras in hope for a solution of the problem, which lie in the personal perspective of the informants themselves.

- Relationships between crime and safety do not follow logically from each other, but seem to be dependent on other socio-spatial aspects, such as the emotional proximity towards a certain place.

- The meaning of a space is constructed. Images of the city space seem to be dependent on other factors then crime rate and experience.

We would argue that assessments of CCTV are dependent on a variety of factors, which cannot be explained through one simple answer. Question (as in polls) that ask simply for support or rejection of CCTV measures are futile, as they do not concern the complex dynamics of perception, construction and spatial imagination. Our hypothesis for further inquiries would be that emotional proximity to a given space will reduce feelings of insecurities and hence the meaning of CCTV as a measure against crime as a source of the former.

The combination of mapping and narrative interviews proved to be very fruitful, in that we could yield a rich set of answers, revealing the contradictory assessments of CCTV beyond simple statements of support or rejection. With these mappings, some of the preconditions of surveillance may be put into new contexts. These preconditions become especially important, if we want to study interdependencies between surveillance measures and their level of acceptance among others. For this it may also be interesting to study aspects of nontechnical surveillance, patterns of social control and their narratives of in/exclusion (c.f.: Zurawski, 2005).

\section{References:}

Appadurai, A. (1996) Modernity at Large, Cultural Dimensions of Globalization. Minnesota: University of. Minnesota Press.

Appadurai, A. (2002) 'The Right to Participate in the Work of the Imagination.' Interview with Arjen Mulder. In: J. Brouwer, A. Mulder and L. Martz (eds.) Transurbanism. Rotterdam V2 / NAI.

Bartels, O. et al. (2001) Dorfanger Boberg: Ein urbanes Quartier am Stadtrand. Hamburg: Dölling \& Garlitz . 
Berger, P.L. and T. Luckmann (2003 [1969]) Die gesellschaftliche Konstruktion der Wirklichkeit. Frankfurt a. M: Fischer Taschenbuch.

Dodge, M. (2005) 'The Role of Maps in Virtual Research Methods.' In C. Hine (ed.) Virtual Methods: Issues in Social Research on the Internet. Oxford: Berg. 113-127.

Fischer, F. and B. Helten (2004) 'What do people think about CCTV. Findings from a Berlin survey.' UrbanEye Working Paper No. 13. http://www.urbaneye.net/results/ue_wp13.pdf

Harvey, M. (2001) The Island of Lost Map:. A True Story of Cartographic Crime. London: Phoenix.

Hess, H. and S. Scheerer (2004) 'Theorie der Kriminalität.' In D. Oberwittler and S. Karstedt (eds.) Soziologie der Kriminalität. Sonderheft 43/2003 der Kölner Zeitschrift für Soziologie und Sozialpsychologie, Wiesbaden.

Hölscher, M. (2003) 'Sicherheitsgefühl und Überwachung. Eine empirische Studie zu Einstellungen der Bürger zur Videoüberwachung und ihrer Erklärung,’ Kriminologisches Journal 35: 42-56.

Hubbard, P., R. Kitchin, B. Bartley and D. Fuller (2002): Thinking geographically. London: Continuum.

Jameson, F. (1995) The Geopolitical Aesthetic: Cinema and Space in the World System. London: BFI.

Jameson, F. (1992) Postmodernism: Or, the Cultural Logic of Late Capitalism. Durham: Duke University Press.

Kitchin, R. and S. Freundschuh (2000) 'Cognitive Mapping.' In R. Kitchin and S. Freundschuh (eds.) Cognitive Mapping. Past, Present, Future. New York: Routledge.

Kitchin, R. (2000) 'Collecting and Analysing Cognitive Mapping Data.' In R. Kitchin, and S. Freundschuh,(eds.) Cognitive Mapping. Past, Present, Future. New York: Routledge.

Kitchin, R. and M. Blades (2002) The Cognition of Geographic Space. London: I.B. Tauris.

Klauser, F. (2005a) 'Raum = Energie + Information. Videoüber-wachung als Raumaneignung.' in: L. Hempel and J. Metelmann, (eds.) Bild - Raum - Kontrolle. Videoüberwachung als Zeichen gesellschaftlichen Wandels, Frankfurt a. M.: Suhrkamp, 189-203.

Klauser, F. (2005b) Die Videoüberwachung als Aneignungsform öffentlicher Räume. Eine Angst-, Sicherheits- und Machtgeographie. Unpublished Dissertation, University of Freiburg/Schweiz.

Koskela, H. (2002) 'Videosurveillance, Gender, and the Safety of Public Urban Space: “Peeping Tom” goes High Tech.’ Urban Geography 23(3): 257-278.

Leopold, N. (2004) 'Überwachung im öffentlichen Raum - eine Gefahr für die demokratische Stadt.' Vorgänge. 1/2004: 29-39.

Löw, M. (2001) Raumsoziologie. Frankfurt a. M.: Suhrkamp.

Lynch, K. (1960) The Image of the City. Cambridge MA: MIT Press.

Reuband, K-H. (2001) 'Videoüberwachung. Was die Bürger von der Überwachung halten.' Neue Kriminalpolitik, 2/2001: 5-9.

Schetsche, M. (2000) Wissenssoziologie sozialer Probleme. Grundlegung einer relativistischen Problemtheorie. Wiesbaden: Westdeutscher Verlag.

Schütz, A. (1971) Das Problem der sozialen Wirklichkeit. Gesammelte Aufsätze Bd. 1, Den Haag: Nijhoff. 
Short, J. R. (2003) The World through Maps: A History of Cartography. Toronto: Firefly Books.

Soja, E.W. (1989): Postmodern Geographies: The reassertion of space in critical social theory. London, New York: Verso.

Statistisches Landesamt Hamburg: HAMBURG.regional 2003 Band 19: Stadtteilprofile.

Zurawski, N. (2005) '“I know where you live!” Aspects of Watching, Surveillance and Social Control in a Conflict Zone (Northern Ireland),' Surveillance \& Society 2 (4): 498-512. http://www.surveillanceand-society.org/articles2(4)/ni.pdf 